\title{
A Review: Prevalence and antimicrobial susceptibility profile of listeria species in milk products
}

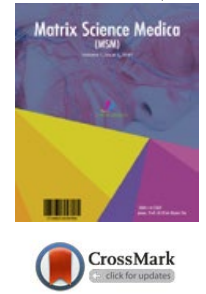

\section{Maliha Sarfraz ${ }^{*}$, Yasmin Ashraf ${ }^{2}$, Samina Ashraf ${ }^{2}$}

${ }^{1}$ Institute of pharmacy, physiology and pharmacology, University of agriculture, Faisalabad, Pakistan

${ }^{2}$ Department of Zoology, University of Punjab, Lahore, Pakistan*Correspondence email. maliha.sarfraz@uaf.edu.pk

This is an open access article distributed under the Creative Commons Attribution License, which permits unrestricted use, distribution, and reproduction in any medium, provided the original work is properly cited.

\section{ARTICLE DETAILS}

Article history:

Received 22 January 2017

Accepted 03 February 2017

Available online 05 February 2017

Key words:

Listeria, milk, antibiotics, prevalence, resistance, foodborne.

\section{ABSTRACT}

More than 200 known diseases are transmitted through food. The causes of foodborne illness include viruses, bacteria, parasites, toxins, metals, prions, and the symptoms of foodborne illness range from mild gastroenteritis to life-threatening neurologic, hepatic and renal syndromes. In the United States, foodborne diseases have been estimated to cause 6 million to 81 million illnesses and up to 9,000 deaths each year. Milk borne pathogens caused serious diseases in the human which may be related to the raw milk, improper pasteurization of milk and milk products. Some biological tools are developed for the measuring of the contamination by the pathogens. Such species like Listeria, Salmonella and Campylobacter species. Such factors which involved in the contamination catalogue between the area where impermanent cattle confinement, low milk production, low milking machine cleaning frequency, and milk storage area.

\section{Introduction}

More than 200 known diseases are transmitted through food. Listeriosis is a severe foodborne disease commonly caused by eating food contaminated with the Listeria species. Genus Listeria has six species that include Listeria monocytogenes, Listeria ivanovii, Listeria seeligeri, Listeria innocua, Listeria welshimeri and Listeria grayi (Jamshidi and Khanzadi, 2011). Two types of species, L. monocytogenes and L. ivanovii, are capable of causing disease in human and animals (Konosonoka et al., 2012). Listeria causes illness in the human which is present in the dairy products including raw milk, cheeses, deli meats and hotdogs. Illness is caused by eating the contaminated food which causes the infection (Atil, Ertas and Ozbey, 2011). L. monocytogenes is the causative agent of foodborne human listeriosis. The presence of listeriosis is usually associated with "YOPI" group that includes young, old, pregnant and immunocompromised individuals. Human listeriosis is severe, with a high mortality rate and infection during pregnancy may lead to abortion or stillbirth (Rudolf and Scherer, 2001)

Recently, Listeria monocytogenes is one of the significant pathogens responsible for food-borne infection. It is frequently implicated in outbreaks of human listeriosis. Pregnant women, newborns, immunocompromised and the elderly persons are at highest risk for listeriosis (Konosonoka, Jemeljanovs et al., 2012). This infection is frequently examined and informed in Europe and North America, but in Africa and other developing countries, only a few sporadic cases have been reported. In Morocco and other countries of North Africa, the studies on the incidence of human listeriosis are rare (E) Marnissi et al., 2013). Emerging food-borne pathogen is called the Listeria monocytogenes because recent studies showed that this microorganism transmitted through food and food products. L. monocytogenes causes listeriosis, a serious transmitted disease which follows as a result of consumption of that food with this pathogenic bacterium. Listeriosis is an important public health concern. The first reports of occurrence of Listeria in food were related to dairy product (Bing et al., 2004).

Listeria monocytogenes became an important foodborne pathogen in 1980s, after numerous food borne outbreaks caused by this pathogen Many reports have verified the food borne listeriosis both sporadic and epidemic cases, almost all varieties of foods. The first reported raw milk and milk products caused listeriosis outbreaks was verified that included 49 cases, seven are fetus and 42 are in immune compromised adults (Wesley et al., 2007). Listeria monocytogenes is gram positive bacteria, facultative anaerobic, non-spore-forming, rod shaped microscopic organisms which have low $\mathrm{G}+\mathrm{C}$ content. It can survive at the tolerant and thrilling conditions such as low $\mathrm{pH}$, low temperature and high salt conditions. Listeria is present in different or many types of environments including soil, water, silage, effluents foods and sewage. (Singh et al., 2012) With increasing the consumption of manufactured ready-to-eat foods in the whole world, Listeria monocytogenes has become known as an important opportunistic human foodborne pathogen (Ponniah et al., 2010).

Listeria commonly present in the dairy environment, on the farm and in the processing plant. On the farm, animals have some pathogens itself, but Listeria is frequently present in manure and fermented silage. Listeria is most abundantly present in the humid areas, stable water including drains, coolers, washing areas and floors (Seyoum et al., 2015). The strong relation between occurrence of L. monocytogenes in raw milk and the infection of the disease frequency was observed. Hence, a decrease in the number of cases per year in all populations was observed when unpasteurized milk was tested. (Latorre et al., 2011). Therefore, prevent from diseases and death related to foodborne microbes remains a main public health challenge. Moreover, global issue is food safety, an increase in export and import of food products could lead to induction and the formation of some new diseases in the geographic ranges that have never proficient foodborne pathogens (Cotter et al., 2001). There are several microbes secreted through the milk, but Listeria monocytogenes is the bacteria which cause problem in public (Cabanes et al., 2005). Listeria monocytogenes is the most important specie in the genus Listeria causing human health threat and spread worldwide with specific host range, includes fish, mammal, crustacean, poultry, and ticks (Peer et al., 2010). The intracellular microorganism focused the association between the infection and developments of the monocytosis in host, which is called as listeriosis in animals. Listeria are small in size, diameter is $0.5 \mathrm{um}$ and length is $15 \mathrm{um}$, rod shaped, no spores or capsule. It is gram positive, facultative anaerobic with both mesophillic and psychotropic. Listeria species are present in the intracellular state within monocytes and neutrophils (Walsh et al., 2001). L. monocytogenes has one to five peritrichous flagella which help in motility, which some time lost as bacteria enter in the human cell. Movement is possible as bacteria polymerize substitute into long acting tails that force bacteria to cytoplasm (Salyers and Whitt, 2002). Old cultures develop filaments which ranging is 6um to 20um in size. Listeria spp. are non-spores and capsules, spread individually and in the form of short chains, $\mathrm{V}$ and $\mathrm{Y}$ letters formed (Mahmood et al., 2001).

Microorganism are very important in food, Listeria monocytogenes recognized as a psychrophilic bacteria. L. monocytogenes caused infection is an extensive zoonosis, affecting mainly goats, sheep, and cattle herds. Listeria species are ubiquitous bacteria commonly spread in the natural environment (Herbert and Foster, 2001). This specificity of the bacteria predictably results in the contamination of various food products. Listeria spp. Is extensively present in the environment and causes listeriosis, a disease that can be severe and is lethal among elderly, younger ones and immune-compromised people, with an estimated $20 \%$ case fatality rate, that might be increase up to $75 \%$ in high risk individuals. The frequency of listeriosis in developed countries is about the 0.2 to 0.8 cases per 100,000 individuals annually. The rate is not so high, but about $20 \%$ is mortality. (Hayat et al., 2008). The contamination of food by L. monocytogenes occurs along the food chain from animal farms. Cross-contamination, which can occur within the environment of food processing equipment, is considered to be a main source of Listeria contamination in processed food. L. monocytogenes is able to attach and survive on various working contact surfaces. One reason may be its ability to form biofilms (Painter et al., 2007). 
monocytogenes among all the listeria species (Meyer Broseta et al., 2003). pitfall of ultrasound (Gravenstein et al., 2007). However, listeriosis caused lots of death after the salmonellosis due to its high fatality rate. The highest rate is hospitalized due to Listeria monocytogenes, which is $91 \%$ among the food borne microorganism. Epidemiological data from different countries showed that the majority of human outbreaks is related to L. monocytogenes among all the listeria species (Meyer Broseta et al., 2003).

\section{Prevalence and antimicrobial susceptibility}

Phan-Thanh et al. (1997) reported that a synthetically characterized media adjusted for best bolstered the development of Listeria species with these development elevating impacts because of the joining of a few fundamental vitamins and development elements: phenylalanine, tryptophan, adenine, histidine, pyridoxal, nicotinamide, calcium pantothenate and paraaminobenzoic acid, all of which had been precluded. Since none of the insignificant media that have been planned so far can bolster the development of all Listeria strains, and the prerequisites for amino acids and vitamins have likewise been appeared to be strain particularly results of digestion system could be utilized to promote portray Listeria species and/or strains. Sergelidis et al. (1997) recommended that L. monocytogenes can survive in various cheddar cheese production processes and can stay reasonable in the last item for a significant time span. In this way, it can be proposed that the polluting sources in Turkish white cheddar cheese ought to be inadequate cleanliness amid draining and assembling process.

Gulmez and Guven, (2001) in this concentrated on, 5 types of Listeria in Turkish white cheddar cheese were disengaged from 7 of 85 cheddar tests. This is, from one viewpoint, equivalent with the consequence of Cecil cheddar (7.5\%), then again is higher than that in aged and saline solution salted Turkish white cheddar $(0 \%)$, however lower than that in the nonmatured Turkish white chedder cheese (15\%). Sagun et al. (2001) proposed the commonness of Listeria spp. have been observed to be $5.11 \%$ in herby cheddar in Van area which is matured and produced generally utilizing an assortment of herbs, for example, Allium spp. This is marginally lower than that in the Turkish white cheddar cheese in our study. In the investigation of Gulmez and Guven (2001), the commonness of L. monocytogenes are 5\% and $2.5 \%$, L. innocua $5 \%$ and $5 \%$ in the non-aged Turkish white and Cecil cheddar, separately. In the non-matured Turkish white cheddar, these two microorganisms were concurrent in $5 \%$ of the specimens. In herby cheddar tests, the pervasiveness of $\mathrm{L}$. monocytogenes were resolved as $3.93 \%, \mathrm{~L}$. ivanovii, L. innocua and L. welshimeri as $0.39 \%$.

Rudolf and Siegfried, (2001) in European red smear cheddar, the frequency of Listeria spp. was resolved as $15.8 \%$, where $6.4 \%$ of the examples were defiled with L. monocytogenes, $10.6 \%$ with $\mathrm{L}$. innocua, and $1.2 \%$ with $\mathrm{L}$. seeligeri. Cordano and Rocourt (2001) reported that 2 of 256 delicate cheddar tests $(0.8 \%)$ were sure for Listeria spp., however in hard cheese, none of 155 specimens $(0 \%)$ were sure for Listeria spp. in Chili. Pak et al., (2002), it has been underscored that the pollution of cheese or deciding items with Listeria spp. is probably because of defilement amid the aging stage post-process tainting from ecological sources and crosspollution in the dairy plant and/or retail locations or lacking handling and colonization of L. monocytogenes in coolers in retail locations. Huppertz et al. (2002) contemplated that cell free concentrates contained dynamic synthase, citrate, isocitrate dehydrogenase, aconitate hydratase, malate dehydrogenase, fumarate reductase, fumarate hydratase, pyruvate dehydrogenase framework, decreased nicotinamide adenine dinucleotide phosphate and oxidases for diminished nicotinamide adenine dinucleotide. Strangely, catalysts for the a-ketoglutarate oxidation framework, succinate dehydrogenase, isocitrate lyase and malate synthase were not distinguished. Cytochromes were likewise not distinguished. They reasoned that the TCA cycle in L. monocytogenes might be part without the change of a-ketoglutarate to succinate and that $\mathrm{L}$. monocytogenes may have a part non-cyclic citrate pathway with an oxidative segment (aconitate hydratase, citrate synthase, isocitrate dehydrogenase) and a reductive bit (fumarate hydratase, malate dehydrogenase, fumarate reductase).

Bandow et al. (2002) is suggested that in the L. monocytogenes it has been demonstrated that specific cell divider focusing on antimicrobials vancomycin, bacitracin and nisins, impel sB action, as sub-deadly introduction brought about a few fold affectation of an opuCAelacZ correspondent combination in a wild sort strain when contrasted with a DsigB mutant. It has been demonstrated that a L. monocytogenes DsigB mutant was impeded in its capacity to develop when presented to subdeadly convergences of ampicillin, penicillin $\mathrm{G}$, and bacteriocins, and was all the more quickly inactivated at higher antimicrobial focuses (Begley et al., 2006).
Tsai et al. (2003) concentrated on contrasts were accounted for by the different creators in the wholesome necessities for development of $\mathrm{L}$. monocytogenes and this could be credited to hereditary and biological differing qualities, and also the underlying physiological condition of the bacterium. For instance, amino acids and vitamin necessities varied relying upon the strains utilized. These distinctions in amino acids and vitamin prerequisites for the different strains could clarify why L. monocytogenes can persevere and get by in an extensive variety of natural conditions. $\mathrm{L}$. monocytogenes Scott A required glucose, glutamine, isoleucine, leucine, arginine, cysteine, methionine, valine, biotin, riboflavin, thiamine and thioctic acids for development, while fructose, cellobiose, maltose, mannose, glucosamine, trehalose, glycerol, $\mathrm{N}$-acetylglucosamine and $\mathrm{N}$-acetylmuramic acid upheld development without glucose. Their concentrate likewise found that chitin and cell dividers of starter microscopic organisms (Lactococcus lactis) upheld the survival of L. monocytogenes proposing another conceivable system for survival in certain sustenance items.

Wemekamp-Kamphuis et al. (2004) More than 200 diseases which are transmitted by a different variety of the food having the microbes include fungi, bacteria, parasites and viruses. Millions of illness are reported in each year in the United States, which is caused by foodborne pathogens. (Ferreira et al., 2003). Although food quantity in the United States is one of the safest in the world, the Centers for Disease Control and Prevention evaluations that 76 million people get sick, 5,000 die more than 300,000 are hospitalized each year from the foodborne illness. The threat of illness due to pathogens in food is increasing day by day over the last 20 years, one fourth person is at high risk of infection today. Interestingly, Moorhead and Dykes (2003) did not discover any connection amongst sB and bacteriocins, in other exploration paper reported that DsigB mutant is more impervious to nisin than the guardian strain. A later study shows a part for $\mathrm{sB}$ in resilience to protein combination restraining antimicrobials (i.e. gentamicin and tetracycline) as MICs for these operators were two-and four-fold lower, individually, for a DsigB mutant. What's more, 18 vancomycin-inducible qualities were appeared to be under $\mathrm{sB}$ control in L. monocytogenes, showing a part in observing and keeping up cell divider honesty.

Winter et al. (2004) proposed that Listeria monocytogenes can bring about mastitis in dairy animals, and it can be shed in the milk of asymptomatic cows, human pollution happens through utilization of crude milk, or items fabricated with crude milk or ingestion of handled sustenance crossdebased with pathogens present in the nourishment preparing plant environment. In dairy cattle, L. monocytogenes can bring about neurological ailment, premature birth, or asymptomatic contaminations. Solid, however tainted creatures, shed Listeria in defecation and fecal pollution of fields or vegetables has been involved as a wellspring of defilement for people and ruminants. Hence, spreading untreated fertilizer onto fields and cropland is viewed as a danger component for L. monocytogenes foodborne malady. Oliver et al. (2005) recommended the commonness of L. monocytogenes in mass tank milk has been accounted for to extend from $1 \%$ to $12 \%$. Listeria monocytogenes causes septicemia and meningitis in people. Pregnant ladies are especially powerless since $\mathrm{L}$. monocytogenes contamination may bring about unconstrained premature births or stillbirth of the hatchling. Listeria monocytogenes has been confined from flying creatures, warm blooded animals, fish, shellfish and bugs. Moreover, L. monocytogenes are boundless in nature and live normally in plants and soil situations. It can develop in an extensive variety of temperature and $\mathrm{pH}$. This versatility empowers $\mathrm{L}$. monocytogenes to develop in refrigerated crude milk and in low quality silage with a pH of 4.5. At high bacterial focuses, L. monocytogenes can survive least HTST sterilization.

Chen Hui Yan et al. (2006) inspected a sum of 45 sustenance tests were analyzed for the nearness of Listeria spp., of which 7 were sure utilizing the global standard strategy and 9 utilizing a changed technique. All strains were distinguished as L. monocytogenes by the API technique. Antitoxin powerlessness testing uncovered that all strains were helpless to vancomycin, midecamycin, erythromycin, sulfamethoxazole, cefazolin, gentamicin, and ampicillin, however, were all impervious to nalidixic acid, cefixime, optochin, cefotaxime and polymyxin B. Forty-one separates of L. monocytogenes, which were acquired from crude burger patties, were tried for their defenselessness against eleven anti-infection agents by utilizing standard plate dispersion strategy Wong et al. (2012). Specifically, 31.7\% of the separates were observed to be not impervious to any of the anti-infection tried, while the rest demonstrated imperviousness to no less than one antimicrobial. The outcome demonstrated that imperviousness to tetracycline was the most widely recognized (46.3\%), trailed by amikacin $(31.7 \%)$, erythromycin (36.6\%) and sulfamethoxazole-trimethoprim (17.1\%). 
spp. was examined in an aggregate of 157 crude milk and dairy item tests sold in Antakya (Antioch). The commonness of Listeria spp. in crude milk and Turkish white cheddar tests were observed to be $2.12 \%$ and $8.23 \%$, aindividually. Listeria monocytogenes was not disengaged from crude drain and found in just two cheddar tests (2.35\%). No Listeria spp. were detached in any of the margarine and yogurt tests. Swaminathan et al. (2007) studied that listeriosis is a serious invasive disease that primarily afflicts pregnant women, neonates and immunocompromised adults. The causative organism, Listeria monocytogenes, is primarily transmitted to humans through contaminated foods. Outbreaks of listeriosis have been reported in North America, Europe and Japan. Soft cheeses made from raw milk and ready-to-eat meats are high risk foods for susceptible individuals. Efforts by food processors and food regulatory agencies to aggressively control L. monocytogenes in the high-risk foods have resulted in significant decreases in the incidence of sporadic listeriosis. Disson et al. (2008) concentrated on that the reason for this expanding frequency, was all the while continuous in 2008, in Austria in any event, is obscure. A sum of 1554 affirmed instances of listeriosis were accounted for from $26 \mathrm{EU}$ part states in 2007. The EU notice rate was 0.3 for each 100000 populaces.

Therefore, fast and perfect identification of Listeria infections is important.

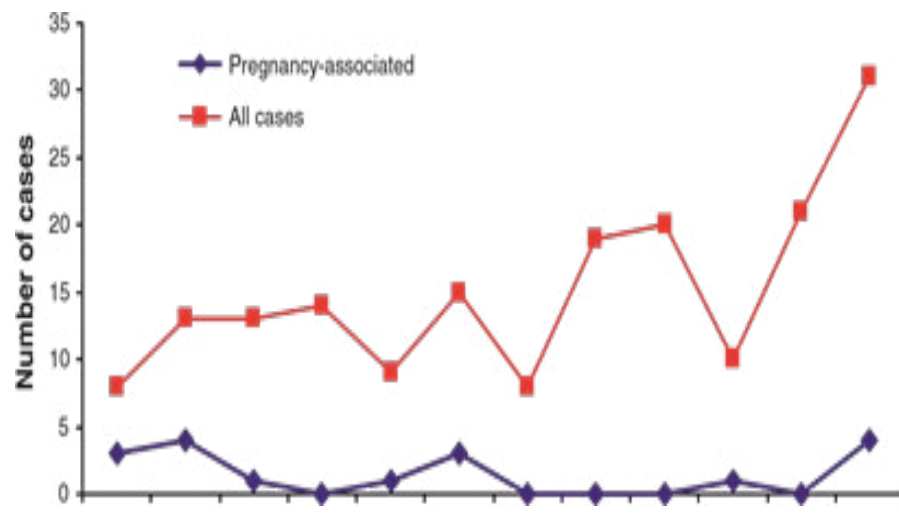

$\begin{array}{llllllllllll}1997 & 1998 & 1999 & 2000 & 2001 & 2002 & 2003 & 2004 & 2005 & 2006 & 2007 & 2008\end{array}$

Figure 1 Absolute number of cases of invasive listeriosis, Austria

Arslan and Ozdemir, (2008) suggested that Listeria monocytogenes was highly resistance to tetracycline but in earlier studied Listeria showed less resistant to tetracycline. Since previous period, tetracycline has been applied in animals, for treating the infections, diseases mostly in dairy farms. Tetracycline was highly resistance to listeria due to general use of the antimicrobial. Listeria is present in different food products which is resistance to many antibiotics and it is transmitted in human which is very vital factor in public health.

Lungu et al. (2009) suggested that to comprehend the capacity of L. monocytogenes to develop and make due in generally various situations, it is vital to decide the dietary necessities and in addition the instruments of supplement uptake and digestion system. A few exploration bunches have detailed synthetically characterized media that backing the development of L. monocytogenes amid high-impact brooding. None of the insignificant media portrayed could bolster the development of all Listeria strains.

Edson et al. (2009) concentrated on Animal and human pathogen L. monocytogenes was disconnected from 26 bolster tests (20.0\%). Poltronieri et al., 2009 reported milk assumes critical part in L. monocytogenes the study of disease transmission in this manner it must be remembered that these unsafe microscopic organisms are acquired the homestead environment by defiled food and in this way additionally on bovine hair, udder, and teat skin and afterward likewise in milk. L. monocytogenes is known as cow mastitis, conjunctivitis, and other sickness bringing on pathogen microorganisms. Evans et al. (2004) demonstrated that Listeria strains confined from contaminations have been discovered additionally in homestead environment in defecation and silage which implies that L. monocytogenes strains found in nature are destructive. Jofre et al. (2009) concentrated on in many living being's vigorous digestion system for the most part includes a complete tricarboxylic corrosive [TCA] cycle, and numerous microscopic organisms are equipped for developing with pyruvate or citrus extract intermediates as the carbon and vitality source. Nonetheless, Trivett and Meyer presumed that amid vigorous brooding neither pyruvate, acetic acid derivation, isocitrate, citrate, a-ketoglutarate, malate or fumarate upheld the development of L. monocytogenes in a characterized medium, and that consideration of these substrates with glucose did not monocytogenes in a characterized medium, and that incorporation of these substrates with glucose did not expand the development of L. monocytogenes contrasted with the development of glucose alone.

Morobe et al. (2009) considered the susceptibilities of all disengages to various antimicrobial specialists were tried by the plate agar strategy as institutionalized by the National Committee for Clinical Laboratory Standards. The accompanying board of antimicrobial plates and focuses were utilized; erythromycin, chloramphenicol, fusidic acid, novobicin (5 g), methicillin (10 g), penicillin G $(1 \mathrm{U})$, streptomycin $(10 \mathrm{~g})$, tetracycline (25 g) (Mast Diagnostics, Merseyside, UK) and in cephalothin, ampicillin, gentamicin, sulphamethaxozole/trimethoprim and nitrofurantoin. They were acquired from the South African Bureau of Standards L. monocytogenes ATCC 19115 was utilized as the reference strain.

Morobe et al. (2009) recommended that the L. monocytogenes was segregated and emphatically distinguished by utilizing morphological and biochemical tests. From a sum of 1324 sustenance tests tried 57(4.3\%) were certain for L. monocytogenes. Out of the 57 secludes of L. monocytogenes 7 (12.3\%), 3 (5.3\%), $0(0 \%), 27(47.4 \%)$ and 20 (35.1\%) were disconnected from cheddar, crude milk, meat (biltong), solidified cabbage and serving of mixed greens, separately. From the 5 topographical regions chose for examining in this study, Gaborone South recorded the most astounding number 19 (33.3\%) of L. monocytogenes confines while Gaborone West recorded the minimum, 7 (12.3\%). The discoveries in this study uncover the nearness of $\mathrm{L}$. monocytogenes serotypes $1 / 2 \mathrm{a}$ and $1 / 2 \mathrm{~b}$ in prepared to eat nourishment and highlight the requirement for instruction and preparing programs in sustenance security in Gaborone, Botswana. This study discovered imperviousness to penicillin G, sulphamethaxozole/ trimethoprim, chloramphenicol, and tetracycline to be 42.11, 29.82, 28.30 and $22.81 \%$, separately. Be that as it may, no disconnect was impervious to fusidic acid, methicillin, erythromycin, cephalothin and ampicillin. L. monocytogenes can grow best at more than $10 \% \mathrm{NaCl}$ concentration. In one research, it reported that listeria monocytogenes lived in $16 \% \mathrm{NaCl}$ for one year period, at $\mathrm{pH}$ 6.0. Additional study suggested that resistance of the L. monocytogenes to common salt strengthen at the lower temperatures. The organism can live 100 days $10.53 \%$ of $\mathrm{NaCl}$ and the temperature is 4oC. Listeria monocytogenes is resistant to the UV radiation, X-rays and gamma rays which seriously contribute to the extensive dispersion of this bacterium.

Fox et al. (2009) suggested that Listeria monocytogenes is a potentially lethal foodborne pathogen commonly found in the environment. European Union hygiene legislation places responsibility for safety on primary production facilities, including farms, as part of a policy to introduce traceability throughout the food chain. This study aimed to determine the occurrence of L. monocytogenes in the Irish dairy farm environment and in particular the milking facility. Two hundred ninety-eight environmental samples were collected from 16 farms in the southern region of Ireland. A number of farms within the group supply raw milk to the unpasteurized milk cheese industry. The samples taken included cow feces, milk, silage, soil, water, etc. Samples were enriched in Listeria enrichment broth and incubated for $48 \mathrm{~h}$, followed by plating on chromogenic agar Listeria and further incubation of the plates for 24 to $48 \mathrm{~h}$. Presumptive L. monocytogenes isolates were purified and confirmed by PCR targeting the hly gene. Overall, 19\% of the samples (57 of 298) were positive for L. monocytogenes. These were serotyped using conventional and PCR methods; serotypes $1 / 2 \mathrm{a}, 1 / 2 \mathrm{~b}$, and $4 \mathrm{~b}$ made up $78 \%$ of the typeable isolates. A correlation was found between the level of hygiene standards on the farm and the occurrence of L. monocytogenes. There was little difference in the occurrence of $\mathrm{L}$. monocytogenes between farms supplying milk to the unpasteurized milk cheese industry and those supplying milk for processing. This study demonstrates the prevalence of L. monocytogenes in the dairy farm environment and the need for good hygiene practices to prevent its entry into the food chain.

Allerberger and Wagner, (2010) recommended that two types of Listeria species, L. monocytogenes and L. ivanovii are connected with listeriosis, which has a brooding time of 1-90 days, with side effects including the runs, agitated stomach, fever, chills, hardened neck, disarray, and muscle throbs. Listeriosis has two logical markers sepsis and meningitis, and it is recognized when monocytosis is seen in cerebrospinal liquid and fringe blood. Nyarko and Donnelly (2015) proposed that greatest conditions are 
created by $\mathrm{L}$. monocytogenes of the serotypes $1 / 2 \mathrm{a}, 1 / 2 \mathrm{~b}, 1 / 2 \mathrm{c}$ and $4 \mathrm{~b}$. $\mathrm{L}$. monocytogenes is a hereditary heterogeneous animal category, with a little portion of strains (serotypes 1/2a, 1/2b, 4b) ensnared in human listeriosis.

Ponniah et al. (2010) said that microorganism enters host mostly through the intestin when food is contaminated with various pathogen is eaten. After that, Listeria monocytogenes contact to host proteolytic enzymes, stomach have $2 \mathrm{pH}$, which shows the acidic environment, non-specific inflammatory attacks and bile salts, generally via the actions of several stress response genes and related proteins. Listeria monocytogenes is then attached and it is effected through host cells with help of a family of the surface proteins that is called internalins. InlB and InlA are the most common, essential virulence genes facilitating invasion and adhesion of the eukaryotic cells.Firstly, The internalins enters in bacteria into non phagocytic cells as epithelial cells, fibroblasts cells and hepatocytes. Fast entry to the host cells permits $L$. monocytogenes to avoid host immune reconnaissance functions.

Following internalization, L. monocytogenes is commonly found in single membrane vacuoles.The listeriolysin 0 , cytolysin pore forming, the thiol enzyme that activated toxin which is vital for Listeria monocytogenes virulence, act as interaction with phosphatidyl choline phospholipase $\mathrm{C}$ who helps the LLO in breaking primary vacuoles, and allow to release of Listeria monocytogenes cells into cytosol. Then, intra cellular development and intra cytoplasmic multiplication take place in the cell. The mobility in cell and spreading of L. monocytogenes cell by cell is mediated by the another protein, which is present in cell surface, ActA enzyme which discriminates actin into the comet tail that passed the bacteria to the cytoplasmic membrane.Enveloped is formed around the bacteria in filopodiuml like structures which are recognize and overcome through adjacent cells, which caused enlargement of the secondary dual membraned vacuoles. An active lysis of secondary double membrane vacuoles signals that involved the establishment of another infection cycle. According this way, L. monocytogenes present in the host tissues are protected from humoral harms of the immune system.

Jamshidi and Khanzadi, (2011) suggested that raw milk has the highest rate of Listeria monocytogenes. In this study, total 100 samples of bulk milk were collected arbitrarily and then delivered to the Pasteurization Factory in Mashhad. Firstly, samples were enriched by using Listeria enrichment broth for the isolation and the identification of L. monocytogenes. For last identification of bacterial colonies, multiplex PCR assay was done by using different primers. These primers are specific for the reputed phophoribosyl pyrophosphate synthetase (prs) gene of Listeria species. $4 \%$ positivity of Listeria monocytogenes was determined from the raw milk and the specificity was $100 \%$ and sensitivity was $3.5 \times 103 \mathrm{cfu} \mathrm{ml}-1$ by this method. Due to the high sensitivity and specificity of multiplex PCR assay,for the identification of bacterial colonies of listeria species specially L. monocytogenes this is useful. Singh et al. (2012) studied that the recent reports showed the immediate detection of Salmonella species and Listeria monocytogenes by PCR curve analysis. The result was two peaks with having the melting temperature of $86.29 \pm 0.13{ }^{\circ} \mathrm{C}$ for Salmonella Species and $86.29 \pm 0.13{ }^{\circ} \mathrm{C}$ for L. monocytogenes of optimal Sybr Green I with specific concentration.

Konosonoka et al. (2012) suggested that in the farm environment, feed was a risk factor of poisoning consequently fresh milk also poisoned with pathogenic microbes of Listeria genus species. The ratio of Listeria ivanovii, Listeria seeligeri and Listeria innocua was $9.2 \%$ and Listeria monocytogens was $20.0 \%$ which were isolated from feed samples. Furthermost different silage $4.7 \%$ and fodders $9.3 \%$ were polluted with the Listeria monocytogenes. Listeria species were isolated mostly from the feed prepared and used in biological dairy farm rather than from conventional dairy farm, respectively $44.4 \%$ and $18.3 \%$. Listeria monocytogenes was not present in bulk milk samples of biological dairy farm.

López-Campos et al. (2012) suggested that the recognition and account of pathogens in food and food processing area are significant factor of any incorporated program to confirm the safety of foods throughout the food supply chain. Government authorities and food companies use microbiological analysis to monitor the state of contamination at all times and evaluate its propensities so as to identify emerging hazards. Microbiological investigation is also a vital tool for testing in accordance with the microbiological measures developed for each food type, and also important being for estimating the actions of different management strategies based on the Hazard Analysis and Critical Control Points (HACCP) system. HACCP has greatly enhanced food safety, but it will not be totally effective until improved methods of analysis are established. These new detection methods are the necessary technologies that will significantly improve our food safety once incorporated in the HACCP. Microbiological analysis of foods is based on the detection of microorganisms by visual, biochemical, immunological, or genetic means, either before enrichment. Altuntas et al. (2012) studied to observed antibiotic sensitivity of the L. monocytogenes strains were isolated from animal derived foods. Disc diffusion assay was used for all fourteen Listeria monocytogenes for checking susceptible to the antibiotics, including vancomycin, penicillin G, tetracycline, rifampicin, chloramphenicol, erythromycin, gentamicin and trimethoprim. Conversely, the ratio of streptomycin and fosfomycin were $92.9 \%$ resistances and $7.1 \%$, correspondingly. These strains were not tested for multiple drug.

Wong et al. (2012) L. monocytogenes is present in food products which caused diseases in humans. Listeria is a possible source of food processing equipment and in processed food (Pak et al., 2002). Listeria monocytogenes can be found in working area of dairy products. It is also able to make biofilms.

Al-Mariri et al. (2013) in this studied total 766 milk samples were collected from different dairy farms. Conventional methods used, 84 samples showed $10.96 \%$ positivity for Listeria spp. The biochemical tests were done for isolated Listeria spp. in which catalase was positive, oxidase was negative, motile and H2S did not produce. The highest occurrence of Listeria spp. was present in raw bovine milk samples $16.2 \%$, sheep's milk samples $12.4 \%$, but in goat milk samples no listeria was found. L. monocytogenes was most abundantly present from raw milk where ratio is $41.6 \%$. Other isolates were L. ivanovii $14.2 \%$, L. innocua $17.8 \%$, L. gravi $4.7 \%$. L. welshimeri $9.5 \%$ and PCR has confirmed our results using the specific 16S rRNA gene and 16S-23S spacer involved in the genotypic identification of Listeria sp. The results of this study indicated the potential risk of the infection with Listeria in people consuming raw and unpasteurized milk and dairy products. Enurah et al. (2013) studied that Listeria monocytogenes is present in fresh raw milk and the abattoir effluents in 6th zones of Nigeria. Bauer- Kirby disc diffusion assay was used for examining the antibiotic resistant pattern of isolates. Total 626environmental and food samples were cultured, on selective media where the positivity for L. monocytogenes was 54 (8.6\%). Bielecki J, (2013) suggested that raw milk is accessible for the sale in every market in Latvia. Hence it is very essential to collect information about the microbial risk issues and some hazards related to raw milk production. The Risk valuation and bacterial monitoring will continue to the play vital role in guaranteeing food safety. Bielecki J et al., (2003) suggested that serious control managing agendas created for the individual milk production farms which depend upon risk analysis, hazard analysis and total quality management, and these principles are very essential for gaining safe and raw milk for the consumers and for the processing.

Tsai and Hodgson, (2013) suggested Listeria monocytogenes can consume limited numbers of carbon sources for the energy with glucose. Thus, this microbe is essentially able to utilize different sources of energy for the survival or growth in gastrointestinal phase e.g. degradation of proteins, polymers of carbohydrates, lipids and nucleic acids. L. monocytogenes is fermentative and consumes sugars for growth and acid production. There is still limited evidence related the metabolic pathways and transport mechanisms which this bacteria uses in fermentation of sugars and the carbohydrate polymers. Al-Mariri et al. (2013) studied that recently, strains of the Listeria monocytogenes are pathogenic to animals and human, whereas Listeria ivanovii are only caused diseases in animals, such as sheep and cattle (Vazquez-Boland et al., 2001). Listeria monocytogenes is recognized in the milk both healthy and infected animals (Wagner et al., 2000). It is also present in contaminated environment of milk processing, poor hygienic environment which causes the milk contamination. Listeriosis is mostly caused by food products such as soft cheeses, products made from unpasteurized milk, and ready to eat meat products.

Jamali et al. (2013) studied, Listeria species were resistant to penicillin G and tetracycline, but some are less resistant to chloramphenicol, amoxicillin acid, clindamycin, kanamycin and erythromycin. Penicillin $G$ and tetracycline was resistance to listeria spp. which is present in food. Nearly about different listeria species were isolated which resistance to the at least one antibiotics but $8.4 \%$ multidrug resistance. The ratio of multidrug resistant isolated spp were $\mathrm{L}$. monocytogenes $71.4 \%$ and $\mathrm{L}$. innocua $28.6 \%$. Listeria monocytogenes is sensitive to rifampicin, vancomycin and gentamicin which results are related to earlier studies but lately reported that $\mathrm{L}$. monocytogenes present in food showed high sensitivity to gentamicin and vancomycin. Al-Mariri et al. (2013) studied genus Listeria, which are mostly spread in the environments and regularly present in the contaminated food. 
Listeria is aerobic, microaerophilic, non sporulating rods, facultative anaerobic and grow in the specific range of temperature. Listeria has been isolated from various ranges of the resources such as plants, soil, water, feces, seafood, meat, decaying vegetables, milk and dairy products. L. monocytogenes is the most important in genus, some other species are $\mathrm{L}$. seeligeri, L. innocua, L. ivanovii, L. grayi and L. welshimeri. Smallest genome of this genus is present in Listeria welshimeri. Listeria monocytogenes is present in milk of the healthy and infected animals. The food products such as yogurt, meat, soft cheeses, and ready to eat products are frequently related to listeriosis.

Cerva et al. (2014) studied that milk borne pathogens spread severe diseases in human which are mostly associated with raw milk, unpasteurized milk and milk products. Some scientific methods are established for measuring of contaminated food by the pathogens. Such as Campylobacter, Listeria species and Salmonella species. Some factors which are involved in contamination index between the region where the impermanent cattle confinement, poor hygienic milking conditions, no cleaning, low milk production, and milk storage regions. Erdősi et al. (2014) have the aim of the present work was to introduce a procedure for the quick detection of Listeria monocytogenes in raw milk and soft cheese via merging of redox potential measurement methods for real time PCR and enrichment in which identification in an easy, time and the cost effective manner. The purpose of this combination was that redox potential measurement, such as an enrichment process, screening that samples which do not have L. monocytogenes. That samples which were positive for L. monocytogenes require another PCR identification. In the enrichment stage that samples which have Listeria monocytogenes screened via redox potential measurement method. But redox potential method was not differentiating between the other B. subtilis and Listeria spp. and from each other.

Saha et al. (2015) suggested that the first report was in 1929 about human listeriosis, and in 1936 first perinatal case was reported. The microorganisms have been reported to the cause disease in an extensive variety of domestic and wild animals, and have been isolated from several species of amphibians, mammals, insects, birds, fish, reptiles and crustaceans. Listeriosis is caused by transmission of microorganism in the body through food, it was recognized. It was not several too large, collective source epidemics of Listeriosis present in Europe and North America through 1980s that implication of foods as per the primary path of spread for human involvement to the Listeria monocytogenes were recognized. However, methods of the transmission for Listeria monocytogenes can include zoonotic, vertical, and nosocomial, it is commonly measured that greatest cases of listeriosis contain food borne transmission.

Seyoum et al. (2015) studied was carried out that in Ethiopia, data related the occurrence of Listeria monocytogenes is incomplete. In this study presented the occurrence of Listeria spp. was $32.6 \%$ and positivity of Listeria monocytogenes was $5.1 \%$ in foods such as pork meat, fish, ice cream, cheese and poultry. Hence, the objective of this study was to check the occurrence of Listeria monocytogenes improved from raw milk and milk products as yoghurt and cheese which is mostly formed in urban of Ethiopia. Romanolo et al. (2015) suggested that 250 death rate, 1600 invasive infection and 1500 hospitalizations per year by listeria species Of those individuals with laboratory confirmed listeriosis, there is a $94 \%$ hospitalization rate and $15.9 \%$ death rate. According this pathogen affects definite groups naturally the aged people, immunocompromised persons, and pregnant women. Hazard of listeriosis in pregnant women is ten times greater than the common people and four times higher in individuals aged sixty-five years or older.

Romanolo et al. (2015) suggested the recent methods to separate Listeria specie were isolated involve classical microbiological culture, and PCR based methods. Additional characterization of the serotype level is done by ELISA, agglutination, and PCR methods. Both and one depending on the methods used, these subtyping and identification techniques can proceeds from more than a few hours to many days. The method that associations serotyping and speciation that occurred at petite time that could be very beneficial in trace back studies and outbreak. The supremacy of this expertise to precisely differentiate Listeria spp with $99.03 \%$ precision and serotypes of L. monocytogenes by $96.58 \%$ accuracy help the outline of FTIR joined with Neuro Developer to food security authorities. Hence, this technique would save money, time and related to outbreaks. Future plans include the variation of further subtypes of Listeria monocytogenes to enhance our identification and library capabilities.

Olaniran et al. (2015) studied that highest resistance was detected against penicillin, nalidixic acid and erythromycin, with all $78(100 \%)$ tested for Listeria species presenting resistance, in which $83.33 \%$ was ampicillin, trimethoprim was $67.95 \%$, nitrofurantoin was $64.10 \%$ and cephalosporin was $60.26 \%$. Garedew et al. (2015) suggested that 57 samples were proceeded in which antimicrobial susceptibility testing of all the 57 samples were confirmed by Listeria monocytogenes. All of them isolates, $31(54.39 \%)$ were found one or more to resistant against antibiotic. Resistant rates to, chloramphenicol, penicillin G, sulphamethaxozole/ trimethoprim, and tetracycline were encountered in 29.82, 28.30, 42.11, and $22.81 \%$, correspondingly. Antibiotic resistance was not coming across for cephalothin, methicillin, ampicillin, fusidic acid and erythromycin. There were 15 dissimilar patterns were observed which were resisted. When food products were tested, frozen salads and cabbage were verified main range of resistance configurations. Resistance patterns from all just one pattern (tetracycline and penicillin G) was the same between all food products that were positive for Listeria monocytogenes. Else, other were unique and atypical resistant patterns for the different food products which observed.

Kevenk and Terzi, (2015) studied were carried out to check the occurrence of L. monocytogenes, by performing the serotyping and investigation of the antibiotic resistance and sensibility patterns in raw milk and its products. 210 total samples of milk and the milk products including white $(n=20)$ and kashar cheese $(n=20)$, white $(n=20)$ white $(n=20)$ butter $(n=20)$, cokelek $(n=10)$, farm cheese $(n=10)$ and kuymak $(n=10)$ were collected from Turkey. All these samples analyzed by using an immunomagnetic separation based culture technique and the strains of Listeria monocytogenes confirmed by the occurrence of hlyA and iap genes via PCR (polymerase chain reaction). Listeria monocytogenes was recognized $5 \%$ in milk samples, serotyped as $1 / 2 \mathrm{~b}$ and $4 \mathrm{~b}$, and $8.2 \%$ in dairy products, serotyped such as $1 / 2 b, 1 / 2 c$ and $1 / 2 a$. Whereas, Listeria monocytogenes was not recognized from kashar, butter and ice cream. The antibiotic susceptibility against ampicillin, erythromycin, amoxicillin, penicillin G, chloramphenicol, tetracycline, vancomycin and oxytetracycline were calculated by the disc diffusion method. In which that $15.3 \%$ were resistant to at minimum one drug and $36.5 \%$ were more than one drug resistant. Between all isolates, tetracycline was mostly resistance encountered $34.6 \%$, penicillin G $23 \%$ resistance and chloramphenicol $25 \%$. In conclusion, those studied showed that consuming unpasteurized and raw milk and dairy products are at the risk of listeriosis in humans.

Seyoum et al. (2015) studied 443 samples of milk and milk product were microbiologically investigated following techniques recommended by the U.S. Food and Drug Administration. The overall occurrence of Listeria species were $28.4 \%$ and the positivity of Listeria monocytogenes was $5.6 \%$. The prevalence of Listeria species cheese was highly contaminated at $60 \%$, raw milk $18.9 \%$, pasteurized milk samples $40 \%$, and yoghurt $5 \%$.

Nyarko et al. (2015) studied that Listeria monocytogenes is a food-borne bacterial pathogen that is associated with $20 \%$ to $30 \%$ case fatality rate. $\mathrm{L}$. monocytogenes is a genetically heterogeneous species, with a small fraction of strains (serotypes $1 / 2 \mathrm{a}, 1 / 2 \mathrm{~b}, 4 \mathrm{~b}$ ) implicated in human listeriosis. Monitoring and source tracking of L. monocytogenes involve the use of subtyping methods, with the performance of genetic-based methods found to be superior to phenotypic-based ones. Various methods have been used to subtype L. monocytogenes isolates, with the pulsed-field gel electrophoresis (PFGE) being the gold standard. Although PFGE has had a massive impact on food safety through the establishment of the PulseNet, there is no doubt that whole genome sequence (WGS) typing is accurate, has a discriminatory power superior to any known method, and allows genomewide differences between strains to be quantified through the comparison of nucleotide sequences. This review focuses on the different techniques that have been used to type L. monocytogenes strains, their performance challenges, and the tremendous impact WGS typing could have on the food safety landscape.

Olaniran et al. (2015) reported that highest resistance was detected against penicillin, nalidixic acid and erythromycin, with all $78(100 \%)$ tested for Listeria species presenting resistance, in which $83.33 \%$ was ampicillin, trimethoprim was $67.95 \%$, nitrofurantoin was $64.10 \%$ and cephalosporin was $60.26 \%$. but fosfomycin was $98.2 \%$, gentamicin was $92.31 \%$ and ciprofloxacin was $96.15 \%$ was sensitive. Pyz Łukasik et al. (2015) study was to determine the microbiological quality of raw cow milk from direct sale points. Raw cow milk samples were collected from 5 randomly selected direct sale points for microbiological evaluation. The samples were analyzed to determine total aerobic bacterial count, somatic cell count (SCC), counts of Enterobacteriaceae, Enterococcus, Escherichia coli, and Staphylococcus, and presence of Salmonella, Listeria monocytogenes, and inhibitory substances. The mean counts of total aerobic bacterial in samples from all 
direct sale points were between $9.2 \times 104$ and $3.6 \times 107 \mathrm{cfu} / \mathrm{mL}$. Milk samples collected from 5 direct sale points revealed counts. Enterobacteriaceae ranging from $6.4 \times 101$ to $1.7 \times 106 \mathrm{cfu} / \mathrm{mL}$. Escherichia coli were detected in 12 milk samples with counts ranging from $5.0 \times 100$ to $1.1 \times 102 \mathrm{cfu} /$ $\mathrm{mL}$. Staphylococcus spp. bacteria were found in all milk samples, at counts ranging from $1.6 \times 103$ to $5.1 \times 104 \mathrm{cfu} / \mathrm{mL}$. Listeria monocytogenes bacteria were detected in 1 sample, and SCC in all samples ranged from 78,000 to $1,730,000 / \mathrm{mL}$. The examined samples did not contain Salmonella rods or inhibitory substances. In the samples examined in this study, international hygiene standards were exceeded for total aerobic bacterial count $(n=48)$ as well as for SCC $(n=19)$. Two milk samples contained pathogenic bacteria (Listeria monocytogenes and Staphylococcus aureus) that pose a potential hazard for consumer health.

Allen et al. (2016) suggested that Interestingly, genomic analysis of L. monocytogenes revealed a number of loci, including genes encoding putative efflux pumps, penicillin binding proteins, autolysins, and cell wall-related proteins, which are regulated or putatively regulated by $\mathrm{sB}$ (Begley et al., 2006). Thus, it is not surprising that sB regulates genes and operons involved in AMR in various Gram positive bacteria. In S. aureus, a DsigB mutant was more sensitive to oxacillin and vancomycin. Singh et al., (2003) studied in Bacillus subtilis, mid-logarithmic phase wild type cultures exposed to rifampin experience a reversible growth arrest partially mediated by $\mathrm{sB}$, in contrast, an isogenic DsigB mutant possessed an extended growth arrest period following rifampin exposure, confirming the role of sB in rifampin tolerance.

\section{Conclusion}

Milk borne pathogens caused serious diseases in the human which may be related to the raw milk, improper pasteurization of milk and milk products. Some biological tools are developed for the measuring of the contamination by the pathogens. Such species like Listeria species, Salmonella species and Campylobacter. Such factors which involved in the contamination catalogue between the area where impermanent cattle confinement, low milk production, low milking machine cleaning frequency, and milk storage area. Recently, Listeria monocytogenes is one of the significant pathogens responsible for food-borne infection. It is frequently implicated in outbreaks of human listeriosis. Different antibiotics were used to check the susceptibility like pencillin, ciprofloxacin, ampicillin, fosfomycin, amoxicillin and gentamycin. Gentamycin and fosfomycin was very sensitive as compare to other antibiotics. So, both can be used in the treatment of listeriosis.

\section{References}

Allen K J, E Wałecka-Zacharska, J C Chen, K P Katarzyna, F Devlieghere, E Van Meervenne, J Bania, 2016. Listeria monocytogenes-An examination of food chain factors potentially contributing to antimicrobial resistance. Food Microbiol, 54, 178-189.

Allerberger $\mathrm{F}$ and $\mathrm{M}$ Wagner, 2010. Listeriosis: a resurgent foodborne infection. Clin Microbiol Infect. 16:16-23.

Al-Mariri A, A A Younes and L Ramadan, 2013. Prevalence of Listeria spp. in raw milk in Syria. Bulg Journal of Vet Medicin., 16:112-122.

Altuntas E G, D Kocan, S Cosansu, K Ayhan, V K Juneja, L Materon, 2012. Antibiotic and bacteriocin sensitivity of Listeria monocytogenes strains isolated from different foods. J Food Nutr. Sci, 3(3): 363368.

Arslan S, and F Özdemir, 2008. Prevalence and antimicrobial resistance of Listeria spp. in homemade white cheese. Food Control, 19(4), 360-363.

Atil E, H Ertas and G Ozbey, 2011. Isolation and molecular characterization of Listeria spp. from animals, food and environmental samples. Vet Med 56:386-394.

Aygun 0 and S Pehlivanlar, 2006. Listeria spp. in the raw milk and dairy products in Antakya, Turkey. Food Control. $17: 676-679$.

Bandow J E, H Brötz, and M Hecker, 2002. Bacillus subtilis tolerance of moderate concentrations of rifampin involves the $\sigma \mathrm{B}$-dependent general and multiple stress response. J. Bacteriol, 184(2), 459-467.

Begley M, C Hill and C G Gahan, 2006. Bile salt hydrolase activity in probiotics. Appl Environ Microbiol, 72(3), 1729-1738.

Bielecki J, 2003.Emerging food pathogens and bacterial toxins," Acta Microbiol Pol, vol. 52, supplement, pp. 17-22.

Bing Y S, L J Tao, Z Q Zhong, 2004. Isolation of Listeria monocytogenes from food and test of drug susceptibility. J China Trop Med, 4(4): 515, 516, 534.

Cabanes D, Sousa S, Cebria A, Lecuit M, Garcia-Del Portillo FG, Cossart P, 2005. Gp96 is a receptor for a novel Listeria monocytogenes virulence factor, Vip, a surface protein. EMBO J ,24:2827-38.

Cerva C, C Bremm, E M dos Reis, A V A Bezerra, M. R Loiko, C E F da Cruz, and F Q Mayer, 2014. Food safety in raw milk production: risk factors associated to bacterial DNA contamination. Trop Anim Health Pro. 46:877-882.

Chen HuiYan, Hong Ji Cheng, Li Yi ,2006. The detection of Listeria in food and results of drug sensitivity test. China Trop. Med, 6(5): 770772.
Cordano A M, and J Rocourt, 2001. Occurrence of Listeria monocytogenes in food in Chile. Int J Food Microbiol, 70, 175-178

Cotter P D, Gahan C G M, Hill C, 2001. A glutamate decarboxylase system protects Listeria monocytogenes in gastric fluid. Mol Microbiol, 40:465-75. Disson O, S Grayo, E Huillet, 2008. Conjugated action of two species specific invasion proteins for fetoplacental listeriosis. 455: 1114-1118.

Edson D C, S Empson, and L D Massey, "Pathogen detection in food microbiology laboratories: an analysis of qualitative proficiency test data, 1999-2007," J. Food Saf, vol. 29, no. 4, pp. 521-530, 2009.

El Marnissi B, L Bennani, N Cohen, A E O Lalami and R Belkhou, 2013. Presence of Listeria monocytogenes in raw milk and traditional dairy products marketed in the north-central region of Morocco. Afr J Food Sci. 7:87-91.

Enurah L U, O O Aboaba, S C U Nwachukwu, C I Nwosuh, 2013. Antibiotic resistant profiles of food (fresh raw milk) and environmental (abattoir effluents) isolates of Listeria monocytogenes from the six zones of Nigeria. Afr. J. Microbiol. Res., 7(34): 43734378.

Erdősi O, K Szakmár, O Reichart, Z Szili, N László, P Székely Körmöczy and P Laczay, 2014. Rapid detection of Listeria monocytogenes in raw milk and soft cheese by a redox potential measurement based method combined with real-time PCR. ACTA VET HUNG, 62(3), 304-316.

Evans K, M Smith, P McDonough and M. Wiedmann, 2004. Eye infections due to Listeria monocytogenes in three cows and one horse, J Vet Diagn Invest, 16(5), 464-469.

Ferreira A, D Sue, C P O'Byrne, KJ Boor, 2003. Role of Listeria monocytogenes $\mathrm{sB}$ in survival of lethal acidic conditions and in the acquired acid tolerance response. Appl Environ Microbiol, 69:2692-8.

Fox E, T O Mahony, M Clancy, R Dempsey, M O'Brien, and K Jordan. 2009. Listeria monocytogenes in the Irish dairy farm environment. J Food Protect, 72(7), 1450-1456.

Garedew L, A Taddese, T Biru, S Nigatu, E Kebede, M Ejo and T Birhanu, 2015. Prevalence and antimicrobial susceptibility profile of listeria species from ready-to-eat foods of animal origin in Gondar Town, BMC Microbiol. 15:100.

Gulmez M, and A Guven .2001. Investigation of Campylobacter, Salmonella and Listeria spp. from Turkish White and Cecil cheese. Kafkas Universitesi Veteriner Fakultesi Dergisi, 7(2), 155-161.

Hayat E, Timinouni M, Ennaji M, Hassar M, Cohen N, 2008. Characterization and antibiotic susceptibility of Listeria monocytogenes isolated from poultry and red meat in Morocco. Infect Drug Resist 1:45-50.

Herbert K C, Foster S, 2001. Starvation survival in Listeria monocytogenes characterization of the response and the role of known and novel components. J Microbiol, 147:2275-84.

Huppertz T, Kelly A L, Fox P F, 2002. Effects of high pressure on constituents and properties of milk: A review. Int Dairy J, 12:561-572.

Jamali H, B Radmehr and K L Thong, 2013. Prevalence, characterisation, and antimicrobial resistance of Listeria species and Listeria monocytogenes isolates from raw milk in farm bulk tanks. Food Control, 34(1), 121-125. Jamshidi A and S Khanzadi, 2011. The presence of Listeria monocytogenes in raw milk samples in Mashhad, Iran. Iran J Vet Res. 11.

Jofre' A, T Aymerich , N Gre 'bol , M Garriga ,2009. Efficiency of high hydrostatic pressure at $600 \mathrm{MPa}$ against food-borne microorganisms by challenge tests on convenience meat products. LWT Food Sci Technol, 42:924-928.

Kevenk T 0 and G Terzi Gulel, 2015. Prevalence, Antimicrobial Resistance and Serotype Distribution of Listeria monocytogenes Isolated from Raw Milk and Dairy Products. J nutr food saf.

Konosonoka I, A Jemeljanovs, B Osmane, D Ikauniece, and G Gulbe, 2012. Incidence of Listeria spp. in dairy cows feed and raw milk in Latvia. ISRN Vet Sci,

Latorre A A, A K Pradhan J A S Van Kessel, J S Karns, K J Boor D H Rice and Y H Schukken, 2011. Quantitative risk assessment of listeriosis due to consumption of raw milk. J Food Prot, 74:1268-1281.

López-Campos G, J V Martínez-Suárez, M Aguado-Urda and V López-Alonso, 2012. Detection, Identification, and Analysis of Foodborne Pathogens: Microarray Detection and Characterization of Bacterial Foodborne Pathogens (pp. 13-32): Springer.

Lungu B, S Ricke, and M Johnson, 2009. Growth, survival, proliferation and pathogenesis of Listeria monocytogenes under low oxygen or anaerobic conditions: a review. Anaerobe, 15(1), 7-17.

Mahmood S, 2001. Feminist theory, embodiment, and the docile agent: Some reflections on the Egyptian Islamic revival. Cultural anthropology, $16(2), 202-236$

Meyer Broseta S, A Diot, S Bastian, J Riviere, O Cerf, 2003. Estimation of low bacterial concentration: Listeria monocytogenes in raw milk. Int J Food Microbiol., 80: 1-15. 
Moorhead S M, and G A Dykes, 2003. The role of the sigB gene in the general stress response of Listeria monocytogenes varies between a strain of serotype 1/2a and a strain of serotype 4c. Current microbiology, 46(6), 0461-0466.

Morobe I, C Obi, M Nyila, B Gashe, and M Matsheka, 2009. Prevalence, antimicrobial resistance profiles of Listeria monocytognes from various foods in Gaborone, Botswana. Afr. J. Biotechnol, 8(22).

Nyarko E, and C Donnelly, 2015. Differentiation of different mixed Listeria strains and also acid-injured, heat-injured, and repaired cells of Listeria monocytogenes using fourier transform infrared spectroscopy. J Food Prot, 78(3), 540-548.

Olaniran A. O, S B Nzimande, and N G Mkize, 2015. Antimicrobial resistance and virulence signatures of Listeria and Aeromonas species recovered from treated wastewater effluent and receiving surface water in Durban, South Africa. BMC microbiology, 15(1), 234.

Oliver S P, B M Jayarao, and R A Almeida, 2005. Foodborne pathogens in milk and the dairy farm environment: food safety and public health implications. Foodborne Pathog Dis, 2(2), 115-129.

Painter J, L Slutsker, 2007. Listeriosis in humans, Chapt. 4. In: Ryser ET, E H Marth, (Eds), Listeria, listeriosis and food safety, 3rd edn. CRC Press Taylor and Francis Group, Boca Raton.Pp. 85109.

PakS I, U Spahr, T Jemmi, M D Salman, 2002. Risk factors for L. monocytogenes contamination of dairy products in Switzerland, 1990-1999. Prev Vet Med., 53: 55-65.

Peer M A, R A Nasir, D K Kakru, B A Fomda, M M Wani and Q N Hakeem, 2010. Listeria monocytogenes meningoencephalitis in an immunocompetent, previously healthy 20-month old female child. Indian J Med. Microbiol., 28:169 171 .

Phan-Thanh L, Gormon T A, 1997. Chemically defined minimal medium for the optimal culture of Listeria. Int J Food Microbiol ,35:91-5.

Poltronieri P, M D de Blasi, and O F D Urso, 2009. "Detection of Listeria monocytogenes through real-time PCR and biosensor methods, Plant Soil Environ, vol. 55, no. 9, pp. 363-369,

Ponniah J, T Robin, M S Paie, S Radu, F Mohamad Ghazali and Y K Cheah, 2010. Detection of Listeria monocytogenes in foods. FOOD RES INT. 17:1-11. Pyz Łukasik R, W Paszkiewicz, M Tatara, P Brodzki and Z Bełkot. 2015. Microbiological quality of milk sold directly from producers to consumers. J Dairy Sci.

Romanolo K, L Gorski, S Wang and C Lauzon , 2015. Rapid identification and classification of Listeria spp. and serotype assignment of Listeria monocytogenes using fourier transform-infrared spectroscopy and artificial neural network analysis. PloS one, 10: e0143425.

Rudolf M, and S Siegfried .2001. High incidence of Listeria monocytogenes in European red smear cheese INT J FOOD MICROBIOL, 63, 91-98.

Sagun E, Y C Sancak, O Isleyici, and K Ekici, 2001. The presence and prevalence of Listeria species in milk and herby cheese in and around Van. Turk J Vet Anim Sci, 25, 15-19.

Saha M, C Debnath, and A Pramanik. 2015. Listeria monocytogenes: An
Emerging Food Borne Pathogen. Int. J. Curr. Microbiol. App. Sci, 4(11), 5272.

Salyers A, and D Whitt, 2002, Salmonella species. Bacterial pathogenesis: a molecular approach, 2nd ed. American Society for Microbiology, Washington, DC, 381-397.

Sergelidis D, A Abrahim, A Sarimvei, C Panoulis, Pr Karaioannoglou, and C Genigeorgis, 1997. Temperature distribution and prevalence of Listeria spp. in domestic, retail and industrial refrigerators in Greece. Int J Food Microbiol, 34, 171-177.

Seyoum E T, D A Woldetsadik, T K Mekonen, H A Gezahegn and W A Gebreyes, 2015. Prevalence of Listeria monocytogenes in raw bovine milk and milk products from central highlands of Ethiopia. J Infect Dev Ctries. 9: 1204-1209.

Singh J, V K Batish and S Grover. 2012. Simultaneous detection of Listeria monocytogenes and Salmonella spp. in dairy products using real time PCRmelt curve analysis. Int J Food Sci Tech. 49:234-239.

Singh S K, I D Clarke, M Terasaki, V E Bonn, C Hawkins, J Squire, and P B Dirks. 2003 Identification of a cancer stem cell in human brain tumors. Cancer research, 63(18), 5821-5828.

Swaminathan B, and P Gerner Smidt. 2007. The epidemiology of human listeriosis. Microbes and Infection, 9(10), 1236-1243.

Tsai H, Hodgson D A, 2003. Development of a synthetic minimal medium for Listeria monocytogenes. Appl Environ Microbiol,69: 6943-5.

Vázquez Boland J A, M Kuhn, P Berche, T Chakraborty, G Domínguez-Bernal, W Goebel and J Kreft .2001. Listeria pathogenesis and molecular virulence determinants. Clin Microbiol Rev 14(3), 584-640.

Wagner T, R H Kretsinger, R Bauerle and W D Tolbert. 2000. 3-Deoxy-Dmanno-octulosonate-8-phosphate synthase from Escherichia coli. Model of binding of phosphoenolpyruvate and D-arabinose-5-phosphate. J. Mol. Biol 301(2), 233-238.

Walsh D, G Duffy, J J Sheridan, I S Blair, D A McDowell, 2001. Antibiotic resistance among Listeria, including Listeria monocytogenes, in retail food. J Appl Microbiol., 90:517-522

Wemekamp-Kamphuis H H, J A Wouters, P P L A de Leeuw ,T Hain , T Chakraborty,$T$ Abee, 2004. Identification of sigma factor sB-controlled genes and their impact on acid stress, high hydrostatic pressure and freeze survival inListeria monocytogenes EGD-e. Appl Environ Microbiol ;70:3457-66.

Wesley I V, 2007. Listeriosis in animals. In:Ryser E T,E H Marth, Listeria, listeriosis and food safety. 3rd edn. CRC Press, Boca Raton, FL, USA. Pp. 5584 Winter P, F Schilcher, Z Bago. 2004. Clinical and histopathological aspects of naturally occurring mastitis caused by Listeria monocytogenes in cattle and ewes. J Vet Med,B 51:176-179.

Wong W C, C F Pui, R Tunung, A Ubong, M S Noor Hidayah, M G Farinazleen, A Noorlis, Y K Cheah, R Son . 2012. Antibiogram pattern among cultures of Listeria monocytogenes isolated from frozen burger patties in Malaysia. Pertanika J.Trop. Agric. Sci., 35(4): 793804. 